www.jmscr.igmpublication.org

Impact Factor 5.84

Index Copernicus Value: 83.27

ISSN (e)-2347-176x ISSN (p) 2455-0450

crossref DOI: _https://dx.doi.org/10.18535/jmscr/v5i3.203

Journal Of Medical Science And Clinical Research

\title{
The Role of Effective Communication and Demonstration in Establishing Good Practices of Contact Lens use among College Students- A Randomized Control Trial
}

Authors

\section{Ms. Kripa Anna Joseph ${ }^{1}$, Dr Sumitha Mary Jacob², Dr Anna Mathew ${ }^{3}$, Mr. John Michael Raj ${ }^{4}$}

${ }^{1}$ Final year MBBS Medical student, MOSC Medical College, Kolenchery, Kochi, Kerala, India

${ }^{2}$ Assistant Professor, Dept of Ophthalmology, MOSC Medical College, Kolenchery, Kochi, Kerala, India

${ }^{3}$ Professor, Dept of Pharmacology, MOSC Medical College Kolenchery, Kochi Kerala 682311 India

${ }^{4}$ Biostatistician, Mediscan Systems, Mylapore, Chennai. Tamil Nadu India

Corresponding Author

\section{Dr Anna Mathew}

Professor, Department of Pharmacology, MOSC Medical College, Kolenchery, Kochi, Kerala, India Email: mosc.research@gmail.com, Tel: +919442221950

\begin{abstract}
Background: Contact lens (CL) is a modified lens generally preferred by young people as they provide a wider field of vision, reduce aberrations, do not fog, boost self-confidence and are more convenient for physical activity. Care and maintenance of CL is imperative to prevent complications such as Contact Lens Associated Red Eye [CLARE], papillary conjunctivitis, dry eye, corneal epithelial microcyst and microbial keratitis.

The practice of good communication skills in the medical profession is integral for compliance to medical advice and education improves knowledge of good practices in CL use.

The purpose of this study is to highlight the importance of good communication in influencing the knowledge about good practice of CL among medical students which in turn can ensure safe CL wear. This is not optimally achieved by simply giving a handout.

Objectives: To assess the effectiveness of an interactive talk and demonstration in establishing good practices of CL use compared to just giving the participant a handout alone using a pre-structured questionnaire for assessment.

Methodology: The study was a randomised controlled trial to assess the use and care of CL among 64 college students using CL. All students who were current CL users for correction of refractive power were recruited to the study, if they gave written informed consent. The sociodemographic data and relevant details of the participants were collected and the knowledge and practice questionnaire on CL use was administered. Each participant was allocated by permuted block randomisation, with allocation concealment, to one of the two arms of the study. Participants in Group A received the printed handout with interactive talk and demonstration regarding CL lens use and care while those allocated to Group B only received the CL information handout. The follow-up questionnaire was administered and the data was analysed using the Mann Whitney U test to see if there was a significant difference between the groups.
\end{abstract}


Results: Out of the 64 students surveyed, 46 (71.9\%) were medical students and 18(28.1\%) were non-medical students and the majority were females (95.3\%). Regarding type of CL, 60.9\% used monthly disposable soft CL, 26, $6 \%$ used yearly replaceable soft CL while 7.8\% used extended wear CL.CL was being used by $17.2 \%$ for more than 5 years, by $54.7 \%$ students for $1-5$ years and $28.1 \%$ for less than a year. Only 39 students $(60.9 \%)$ followed the recommended method of hand washing and only 42 (65.6\%) students correctly followed the ideal method of cleaning contact lens.

Complications during CL use were reported by 24 students (37.5\%) of whom only 16 students (66.6\%) immediately consulted the doctor.

There was a significant improvement in the learning scores of students of Group A, who received the interactive talk, demonstration and questionnaire compared to Group B. $(p<0.001)$

Conclusion: The study highlights the importance of good communication in educating CL wearers about good practices of CL use, as it significantly improved the learning scores of the taught group while this was not optimally achieved by simply giving a handout alone.

Keywords: Contact lens, complications, CLARE, patient communication, medical students.

\section{Introduction}

Contact lens (CL) is a modified lens designed to be worn on the eye and is largely used to correct refractive errors.

Globally, youngsters comprise the bulk of CL users. ${ }^{(1)}$ It has become very popular among college students. ${ }^{(2)} \mathrm{CL}$ are preferred over spectacles as they provide a wider field of vision, reduce aberrations, do not fog, boost one's self confidence and are more convenient while involved in sports. The Singapore contact lens study \& the study from KMC, Mangalore showed that most users were in the age group 21 to 30 years and 17 to 22 years respectively. ${ }^{(1,3)}$

Care and maintenance of CL is imperative for safe CL wear.CL is bathed in tears and lies in intimate contact with the eyes, hence with time they get soiled. Therefore it is important to ensure that the user practices the recommended lens care regimen and a failure to do so can result in complications. $^{(4,5,6)}$

Inspite of advancements in CL design and material, $79.3 \%$ of users in the KMC study experienced problems. ${ }^{(3)}$ The possible CL related complications include Contact Lens Associated Red Eye [CLARE], papillary conjunctivitis, dry eye, corneal epithelial microcyst and microbial keratitis. These undesired effects can be reduced if wearers are properly instructed about the use and care of CL and educated about the consequence of CL related complications. Various CL studies conducted among medical students in
Maharashtra, Karnataka and Universities of Selangor and Kuala Lumpur, concluded that improper lens wear and care practice prevailed even among knowledgeable medical students which inturn resulted in complications. . $^{(2,7,8,9)}$

Non-compliance may be intentional or nonintentional. When non-compliance is intentional, the patient does not comply despite his/her knowledge about what is required. In the second group are the patient who do not comply unintentionally, usually because of lack of comprehension, that is, a product of poor doctorpatient communication ${ }^{\cdot(10,11)}$

The practice of good communication skills in the medical profession is integral for the development of meaningful and trustworthy relationship between the doctor and patient and, thus, is beneficial to both of them. ${ }^{(12)}$

The World Health Organization proposes that adherence of patients to recommended guidelines is affected by the following factors: 1) health care system or provider-patient relationship, 2) disease, 3) treatment, 4) patient characteristics, and 5) socioeconomic factors. ${ }^{(13)}$

The practice of good communication skills in the medical profession is integral for the development of meaningful and trustworthy relationship between the doctors and patients and, thus, is beneficial to both of them. ${ }^{(12)}$

Successful communication should be uncomplicated, specific, use some repetition for reinforce- 
ment, minimize jargon and check patient understanding of what has been taught.

In addition, communication should simultaneously employ a patient-centred approach and interpersonal interaction to promote patient satisfaction. ${ }^{(14)}$

Although much emphasis has been put on the importance of effective communication and good doctor-patient relationship in affecting patient health outcomes and satisfaction, physician satisfaction with their professional life can also be an important determinant of a good doctor patient relationship. $^{(16)}$

The purpose of this study is to highlight the importance of good communication in influencing the knowledge and practice of CL use which is not optimally achieved by simply giving a handout and this can inturn ensure safe contact lens wear.

\section{Methodology}

This study is an open label, randomised controlled trial to assess the use and care of contact lens among 64 college students who are using CL. Institutional review board and Ethics committee approval were obtained. Medical students who fulfilled the selection criteria and gave written informed consent were recruited into the study by permuted block randomization using computer generated blocks of four using sealed opaque envelopes. The allocation was concealed from the investigator.

Inclusion Criteria: All students in the selected colleges who are currently using CL for correction of their refractive power.

Exclusion Criteria: Students using CL for cosmetic reasons alone or for other therapeutic indications apart from correction of refractive error, such as perforated corneal ulcers.

Sample Size: The sample size was calculated using n Master 2.0 software ${ }^{(15)}$ using the nonparametric two group Wilcoxon Mann Whitney U - Test. The sample size for $80 \%$ power and $5 \%$ alfa error is 32 subjects in each group.

Study groups: There are two arms to the study. Participants of Group A received the printed CL handout along with interactive talk and demonstration regarding CL use and care and those in Group $B$ received only the CL information handout.

Study Procedure: The socio-demographic data was collected and all students were administered the questionnaire containing questions on knowledge and practice of CL use. The participants allocated to group A were given the printed contact lens information handout and were requested to read it. They then received a demonstration and an interactive talk regarding proper use and care of CL using the principles of effective communication and counselling. The participants in Group B were given the CL information handout alone with no explanations or interactions or demonstration on it. Later the questionnaire was given to both the groups. The Mann Whitney U test was performed using SPSS computer software to find out whether there was a difference in the mean knowledge and practice scores obtained by the students who received the good communication and those that received only the handout.

Consort Flow Diagram

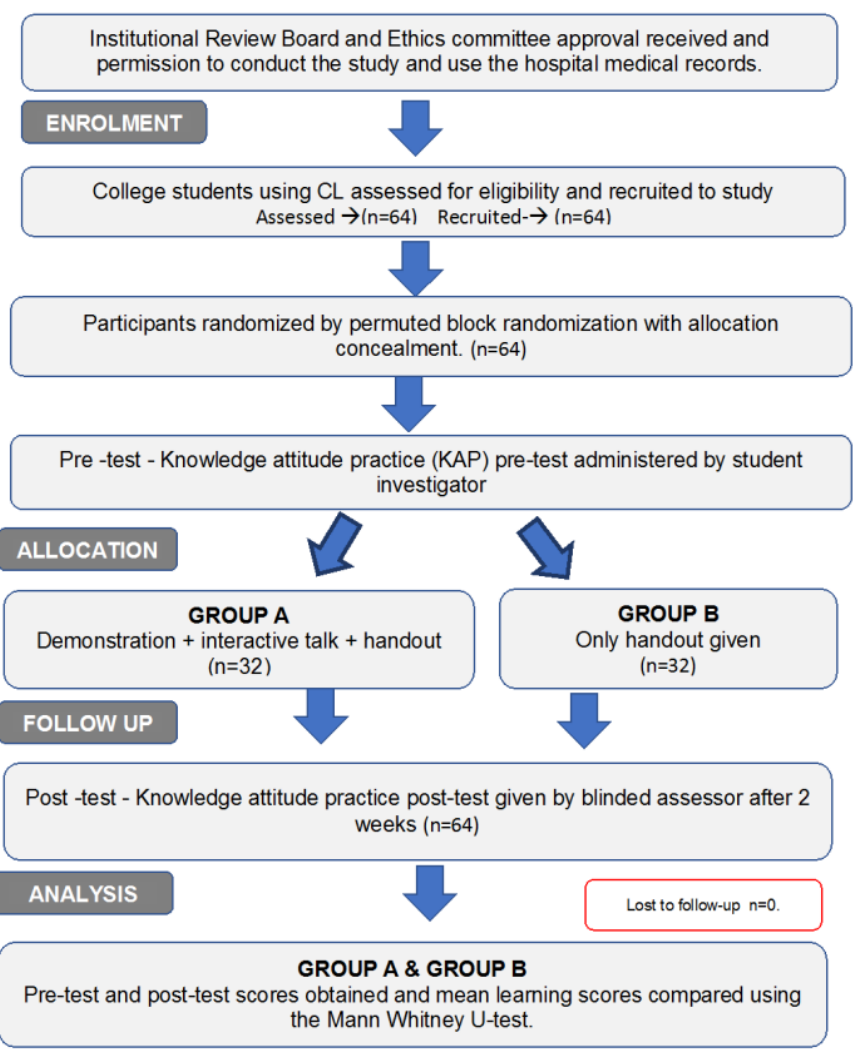




\section{Result}

Table 1. Characteristics of the Selected Participants

\begin{tabular}{|l|c|c|c|}
\hline & Group A & Group B & Total \\
\hline Students & & & \\
Medical & $21(65.6 \%)$ & $25(78.1 \%)$ & $46(71.9 \%)$ \\
Non-medical & $11(34.4 \%)$ & $7(21.9 \%)$ & $18(28.1 \%)$ \\
\hline Mean Age & 21.31 years & 22.56 years & 21.94 years \\
\hline Gender & $31(96.9 \%)$ & $30(93.8 \%)$ & $61(95.3 \%)$ \\
Female & $2(6.3 \%)$ & $3(4.7 \%)$ & $3(4.7 \%)$ \\
Male & & & \\
Type of CL Used & $0(0 \%)$ & $1(3.1 \%)$ & $1(1.6 \%)$ \\
DailyDisposable CL & $18(56.3 \%)$ & $22(68.8 \%)$ & $40(62.5 \%)$ \\
MonthlyDisposable CL & $1(3.1 \%)$ & $1(1.6 \%)$ & $1(1.6 \%)$ \\
QuarterlyDisposable CL & $11(34.4 \%)$ & $6(18.8 \%)$ & $7(26.6 \%)$ \\
Yearly Disposable CL & $2(6.3 \%)$ & $3(9.4 \%)$ & $5(7.8 \%)$ \\
Extended wearCL & & & \\
\hline Years of CL Use & & $5(15.6 \%)$ & $18(28.1 \%)$ \\
Less than 1 year & $22(68.8 \%)$ & $22(68.8 \%) 5($ & $35(54.7 \%(2) 8$. \\
1-5 year & $5(15.6 \%)$ & $15.6 \%)$ & $11(17.2 \% \%)$ \\
More than 5 years & & & \\
\hline Basic Hygiene of Hand Washing & $7(21.9 \%)$ & $7(21.9 \%)$ & $14(21.9 \%)$ \\
Water rinse & $1(3.1 \%)$ & $1(3.1 \%)$ & $2(3.1 \%)$ \\
Alcohol rub & $21(65.6 \%)$ & $18(56.3 \%)$ & $39(60.9 \%)$ \\
Soap water wash & $6(18.8 \%)$ & $9(14.1 \%)$ \\
Multipurpose solution wash & & & \\
\hline Cleaning contact lenses & $18(56.3 \%)$ & $24(75 \%)$ & $42(65.6 \%)$ \\
Correct method & $14(43.75 \%)$ & $8(25 \%)$ & $22(34.375 \%)$ \\
Incorrect method & $2.53 \pm 1.14$ & $0.38 \pm 1.13$ & $1.45 \pm 1.56$ \\
\hline Mean Improvement of Scores & & & \\
(Post test score-pre-test score) & & & \\
\hline & & & \\
\hline
\end{tabular}

Out of the 64 students surveyed, 46 (71.9\%) were medical students and 18(28.1\%) were non medical students. Majority of the CL users were females (95.3\%). Monthly disposable soft CL were used mostly $(62.5 \%)$, followed by yearly replaceable soft CL (26.6\%) and extended wear CL (7.8\%). Of the 64 participants, $28.1 \%$ have been using it for less than a year, $54.7 \%$ have been using CL for 1-5 years and $17.2 \%$ of them for more than 5 years.

The basic hygiene recommendation of washing hand with soap and water before handling CL were followed by $39 \mathrm{CL}$ wearers $(60.9 \%)$. The rest followed the incorrect methods such as washing hands thoroughly with water $(21.9 \%)$, washing hands with multipurpose solution (14.1\%) and using alcohol rub to clean hands (3.1\%).

The ideal method of cleaning CL is to remove the lens from the eye, rub both sides of the lens with multipurpose solution (MPS) and then place them in the lens case which contains MPS. The ideal method was followed correctly by 42 CL users (65.6\%).

Complications while using CL were reported by $24 \mathrm{CL}$ users $(37.5 \%)$ and $40 \mathrm{CL}$ wearers $(62.5 \%)$ reported no complications while using CL. The complications reported included red eyes with CL use $(6.3 \%)$, general discomfort $(4.7 \%)$, dry eyes( $3.1 \%)$,itching of eyes (3.1\%), foreign body sensation(3.1\%) and poor vision(1.6\%). Of the CL wearing students who developed complications, only $16 \mathrm{CL}$ wearers (25\%) immediately consulted the doctor.

Figure 1 shows the mean pre-test and post-test scores of the knowledge and practice questionnaire administered to the CL wearers. Post test scores improved significantly in the group that received the counselling. 
Figure 1. Comparison of Pre-test and Post-test Scores of the Contact Lens Wearers

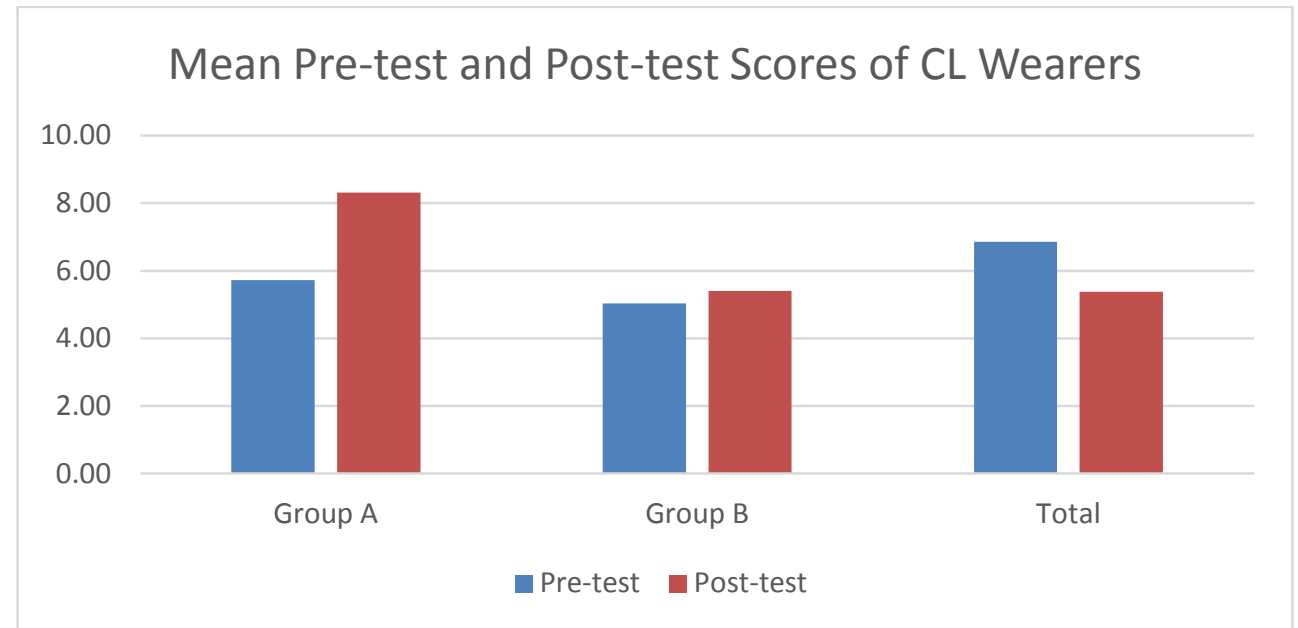

Our study also analysed the improvement in scores of knowledge based questions between two groups, Group A which received the interactive talk, handout and demonstration on CL use and care had a mean improvement score (learning score) of $2.53 \pm 1.14$ compared to the Group B, whose learning score was $0.38 \pm 1.13$. Thus there was a significant improvement in the score in group A as seen in the hypothesis test summary given below.

Table 2. Hypothesis Test Summary

\section{Hypothesis Test Summary}

\begin{tabular}{|c|c|c|c|c|}
\hline & Null Hypothesis & Test & Sig. & Decision \\
\hline 1 & $\begin{array}{l}\text { The distribution of Learning score is } \\
\text { the same across categories of } \\
\text { Group. }\end{array}$ & $\begin{array}{l}\text { Independent- } \\
\text { Samples } \\
\text { Mann- } \\
\text { Whitney U } \\
\text { Test }\end{array}$ & .000 & $\begin{array}{l}\text { Reject the } \\
\text { null } \\
\text { hypothesis. }\end{array}$ \\
\hline
\end{tabular}

\section{Discussion}

The study surveyed 64 students who are CL users. The majority of them were females(95.3\%).This is similar to the study conducted in colleges in coastal Karnataka by B. Unnikrishnan where $79.5 \%$ were females. ${ }^{[3]}$.The choice of type of $\mathrm{CL}$ used is disposable soft contact lens $(60.9 \%)$ and the study conducted in SEGI university, Malaysia had participants mostly using disposable soft contact lens $(68 \%){ }^{[8]}$ Student participants mostly have been using CL for one to five years (54.7\%)and in a study among medical students in Chettinad Institute, Tamil Nadu the users mostly have been using contact lens for less than one year $(67 \%){ }^{[11] .}$

Complications on using CL were present among $24 \mathrm{CL}$ using students (37.5\%), which included red eyes $(6.3 \%)$, general discomfort $(4.7 \%)$,dry eyes
(3.1\%) and poor vision (1.6\%).The study conducted in a rural medical college in Loni, Maharashtra on knowledge and practice of CL wear too had students having complication such as general discomfort $(43.1 \%)$, redness $(20.68 \%)$ while $36.2 \%$ had no complication while using CL. ${ }^{[2]}$

The present study mainly emphasized the importance of good communication while giving instructions on $\mathrm{CL}$ use, care and attention to provide a proper demonstration of $\mathrm{CL}$ use and care along with the printed handout and thus reduce the complications associated with CL use. Printed instructions are often not read and compliance to proper use can be ensured only by counselling the patient using effective means of communication. 


\section{Conclusion}

The study highlights the importance of good communication in educating CL users about good practices in CL use. CL wearers who received the interactive talk, demonstration together with the handout significantly improved their learning scores compared to those who received only the handout. Good communication is not optimally achieved by simply giving a handout alone.

\section{Acknowledgement}

The authors are grateful to the Dean and Management of MOSC Medical College for all the support and encouragement given.

\section{References}

1. Lee YC, Lim CW,Saw SM, Koh D. The prevalence and pattern of contact lens use in a Singapore community CLAOJ Official Publ Contact LensAssoc ophthalmol. inc.2000 Jan 26\{1\}:21-5. CLAO

2. Giri PA, Chavan WM, Phalke DB, Bangal SV. Knowledge and Practice of Contact Lens Wear and Care Among Contact Lens Users Medical Students of Rural Medical College, Loni, Maharashtra, India. Int J Biol Med Res. 2012;3(1):1385-1387.

3. Unnikrishnan B, Hussain S. Pattern of use of contact lens among college students: A cross-sectional study in coastal Karnataka. Indian J Ophthalmol 2009;57\{6\}:467-469.

4. Donshik PC, Ehlers WH, Anderson LD, Suchecki JK. Strategies to better engage educate and empower patient compliance and safe lens wear compliance. Eye contact lens 2007 ;33(6 Pt 2):430-433;434.

5. Hickson-Curran S, Chalmers RL, Riley C. Patient attitudes and behaviour regarding hygiene and replacement of soft contact lenses and storage cases. Contact lens Anterior eye $\mathrm{J} \mathrm{Br}$. Contact lens Assoc. $2011 ; 34(5): 207-15$.

6. Wu Y, Carnt N, Stapelton F. Contact lens user profile attitudes and level of compliance to lens care. Contact lens
Anterior eye $\mathrm{J}$ Br contact lens Assoc. 2010 Aug ;33(4):183-8.

7. Mahadevan G, Arunkmar S, Srushti D S, Suranagi P Ocular health educationKnowledge attitude and practice of contact lens usage among medical students $\mathbf{J}$ Educational Res\& Med each 2014;2(2):268.

8. Mun Yee C, Xuan LY,Kavitha A, Govindarajan P, Ming TJ, Lin TK ,Thampypillai V. Knowledge practices and compliance during contact lens wear among students in Segi University, Kota Damansara, Selangor.SEGI Review ISSN 1985- 5672.2013: Vol 6.

9. Tajunisah I, Ophth M, Reddy SC, Phuah SJ. Knowledge and practice of contact lens wear and care among medical students of University of Malaya. Med J Malaysia. 2008 Aug;63(3):207-10.

10. Sidharam Janti, C. Charanya, AM Raja, Adnan Matheen, R Pandurangan. Knowledge attitude and practise of contact lens users among medical college students in Tamil Nadu. International journal of scientific study, Sept 2014:2\{6\}.

11. Ahmed G. Elzubier, Doctor Patient Communication; A skill needed in Saudi Arabia. J Family community Med. 2002 Jan -Apr;9(1);51-56. Piyush Ranjan, Archana Kumari, Avinash Chakrawathy. How can doctors improve their communication skills. Journal of Clinical and diagnostic Research. 2015 Mar 9(3): JE01-JE04.

12. Kelly B, Haskard Zoinierek, M. Robin Dimatteo; Physician Communication and Patient Adherence to treatment: a Metaanalysis; HHS Public Access Med Care. 2009 Aug; 47(8):826-834.

13. Ann King, Ruth B. Hoppe; Best Practice For Patient -Cantered Communication : a Narrative Review; Journal of Graduate Medical Education .2013 Sep;5(3):385393. 
14. Ajay Kumar Shukla, Veerendra Singh Yadav, Nira Kastury. Doctor- Patient Communication: an important but often ignored aspect in clinical Medicine: Journal, Indian Academy of Clinical Medicine July -September, 2010:11:3.

15. Sample size measured using nMaster Sample size calculation computer software, Version 2, produced by Department of Biostatistics, Christian Medical College, Vellore. 632002 Tamil Nadu India. 